\title{
A protocol of homozygous haploid callus induction from endosperm of Taxus chinensis Rehd. var. mairei
}

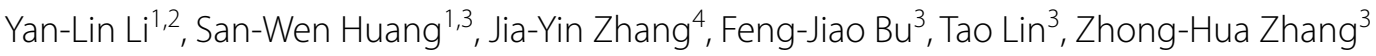 \\ and Xing-Yao Xiong ${ }^{1,3^{*}}$
}

\begin{abstract}
Obtainment and characterization of the novel endosperm callus of Taxus chinensis Rehd. var. mairei are valuable for haploid breeding, genome, and functional genome in Taxus. Callus was obtained by hydropriming with sterile water for 3 days and suitable medium composition. The highest callus induction (70.89\%) and lower browning ratio (7.95\%) were obtained from Gamborg $\left(B_{5}\right)$ medium supplemented with $30 \mathrm{~g} \mathrm{I}^{-1}$ of sucrose, $2.5 \mathrm{mg} \mathrm{I}^{-1}$ of 2,4-dichlorophenoxyacetic (2,4-D), $0.5 \mathrm{mg} \mathrm{I}^{-1}$ of 6-benzylademine (6-BA) and $7 \mathrm{gl}^{-1}$ of agar under dark conditions. The auxin of 2,4-D had a better efficiency of callus induction than naphthylacetic acid, and over $1 \mathrm{mg} \mathrm{I}^{-1}$ of 6-BA was inhibitory to the callogensis of endosperm. The endosperm callus was haploid which was detectable by the flow cytometry. The genome block of homozygosity of callus was homozygous which was indicated by PCR-based SNP marks. The homozygous haploid of endosperm callus in vitro culture may be useful tools for taxoid-metabolism of gene engineering and bio-fermentation engineering.
\end{abstract}

Keywords: Taxus, Haploid, Endosperm, Callus initiation, Homozygote, SNP mark

\section{Background}

Taxus plants are well-known by their ornamental values, cancer-inhibitory alkaloid paclitaxel (Taxol), and timber uses (Xi et al. 2014). As an effective curing cancer of chemical compounds for 50 years (Foa et al. 1994; Bi et al. 2014), the same difficulties with other supply of active compounds: limited quantity of active compounds in tissues, low growth rate, limited localization of active ingredients in the specific organs, and destruction of the nature resource (Kazmi et al. 1991; Frense 2007; Hussain et al. 2013). Additionally, chemical synthesis, semisynthesis, heterologous expression systems, and plant cell culture are the main available resources for harvesting of taxoids, especially paclitaxel (Howat et al. 2014). However, the structure complexity, incomplete biosynthetic

\footnotetext{
*Correspondence: xiongxingyao@caas.cn

${ }^{3}$ The Institute of Vegetables and Flowers, Chinese Academy of Agriculture Sciences, Beijing 100081, People's Republic of China
}

Full list of author information is available at the end of the article pathway and exogenous genes that lead to growth retardation due to taxadiene toxic, which caused producing low yields and numerous toxic side products by chemical synthesis, sim-synthesis, and heterologous expression systems (Howat et al. 2014; Li et al. 2014). The plant cell culture is seen as a successful approach of production paclitaxel without geographical and seasonal variations, and providing paclitaxel with continuous and uniform quality (Howat et al. 2014), while this issued with genetic instability, heterogeneous culture, low growth rates compared to bacterial (Kolewe et al. 2008). Bridging the simsynthesis including of heterologous expression systems and plant cell culture will be allowed large-scale access to taxol compound, and analyzing the paclitaxel metabolisms pathway remain an important goal (Howat et al. 2014). Artificial cultivation of haploid materials (including of callus and haploids), which have been useful in research areas as mutation studies, gene mapping and genomics and as targets for transformation, may accelerate the realization of this goal. 
Haploids are sporophytes of higher plants with gametophytic chromosome number ( $\mathrm{n}$ instead of $2 \mathrm{n}$ ), and it rarely occurs spontaneously which can be induced through several methods, such as in vivo pollination methods (wide hybridization, chromosome elimination, pollination with irradiated pollen and so on) and immature gametophytes (Germanà 2011). Endosperm as a storage tissue for nutrients which is a unique feature of flowering plants in angiosperms, and it is formed during a double fertilization event. Therefore, the embryo is diploid (2C) and the endosperm is triploid (3C) (Wang et al. 2009; Thomas and Chaturvedi 2008). Other seed plants (gymnosperms) of endosperm, as a nutritive tissue supporting the embryo growth, arises from the haploid (1C) cells of the female gametophyte (Wang et al. 2009). In this study, we investigated the effects of hydropriming, media compositions, auxins and cytokinins on endosperm callus induction of Taxus chinensis Rehd. var. mairei, and fully dissect the ploidy level and the genomic homozygosity of them.

\section{Methods}

\section{Plant material}

Fruits and twigs with needles of $T$. chinensis Rehd. var. mairei were collected from natural habitats in China in December, 2012. Seeds were stored at $4{ }^{\circ} \mathrm{C}$ after natural drying. Twigs with leaves, which were kept at $4{ }^{\circ} \mathrm{C}$ for no more than 7 days, were used as materials for FMC, DNA extraction and PCR amplification analysis. After the outer seed coat was removed, the seed with inner seed coat was surface-sterilized in $70 \%(\mathrm{v} / \mathrm{v})$ ethanol for $30 \mathrm{~s}$, followed by a soaking in $0.1 \% \mathrm{HgCl}_{2}$ for $10 \mathrm{~min}$. Subsequently, they were rinsed for several times in sterile water to completely remove the sterilizing agent.

\section{Basic medium}

Six culture media were tested as follows: BLG, $\mathrm{B}_{5}, \mathrm{MS}$, WPM, SH and 1/2MS. All six basic media contained $2.5 \mathrm{mg} \mathrm{l}^{-1}$ of 2,4-D, and $0.5 \mathrm{mg} \mathrm{l}^{-1}$ of 6-BA. Culture medium was solidified with $0.7 \%$ agar and supplemented with $3 \%(w / v)$ sucrose. After sterile seed with inner coat was immersed in sterile water for 1 day, endosperm was aseptically excised from embryo using forceps and a scalpel, and then it was transferred onto the culture medium. The highest callus ratio and lowest brown ration were considered as option index for estimation of optimal basic medium. All treatments were performed in triplicate, and each treatment consisted of 50 plantlets.

\section{Pre-treatment and illumination}

Sterile seeds with inner coat were soaked in sterile water for $0,1,3,5$ and 7 days, respectively. They were used as endosperm donors for the callus induction. The optimal hydropriming time was selected. The efficiency of sterile water and sterile gibberellin III solution ( $3 \mathrm{mg} \mathrm{l}^{-1}$ of $\mathrm{GA}_{3}$ ) for 3 days on callus induction was compared. And effect of light condition with incubating in a growth chamber under a 16:8 h photoperiod at $112 \mu \mathrm{mol} \mathrm{m} \mathrm{m}^{-2} \mathrm{~s}^{-1}$ light provided by fluorescent lamps and darkness on callus induction was investigated. Endosperm was divided into two pieces by forceps and a scalpel without embryo, and then transferred onto $B_{5}$ medium supplemented with $2.5 \mathrm{mg} \mathrm{l}^{-1}$ of 2,4-D and $0.5 \mathrm{mg} \mathrm{l}^{-1}$ of 6 -BA. All treatments were performed in triplicate, and each treatment consisted of 50 plantlets.

\section{Effects of plant growth regulators}

After soaking in sterile water for 3 days, endosperm was divided into two pieces by forceps and a scalpel without embryo. The $\mathrm{B}_{5}$ medium was supplemented with $0.5 \mathrm{mg} \mathrm{l}^{-1}$ of 6-BA and 1.0-4.5 $\mathrm{mg} \mathrm{l}^{-1}$ of 2,4-D or naphthylacetic acid (1.0-4.0 $\mathrm{mg} \mathrm{l}^{-1}$ of NAA), respectively (Table 2). $\mathrm{B}_{5}$ basic medium supplemented with $1.0 \mathrm{mg} \mathrm{l}^{-1}$ of 2,4-D and $0.5-10 \mathrm{mg} \mathrm{l}^{-1}$ of 6-BA was used for callogensis (Table 3). After callogenesis, callus was transferred to fresh medium every 10-15 days. All treatments were performed in triplicate, and each treatment consisted of 50 plantlets.

\section{FCM analysis}

Nuclear suspensions of samples for flow cytometry (FCM) were prepared according to a previously reported method with minor modification (Doležel et al. 2007). The nuclear DNA content was determined using approximately $0.5 \mathrm{~g}$ leaves of mother plant, or 4-week-old callus. The raw materials for FCM analysis were finely chopped in $1 \mathrm{~mL}$ Otto I buffer in a petri dish at $4{ }^{\circ} \mathrm{C}$. Final volume of each sample was adjusted to $500 \mu \mathrm{l}$ after centrifugation. The ploidy level was determined by DAPI staining on a Partec CYFlow space. The staining solution, $500 \mu \mathrm{l}$ DAPI-RNase solution $(50 \mathrm{mg}$ DAPI $l^{-1}+2$ mg RNase $\left.l^{-1}\right)$, was added to each sample. The mother-plant T. chinensis Rehd. var. maire $i$ was used for the size standard of the ploidy level. All treatments were performed in triplicate. 


\section{DNA extraction and PCR amplification}

According to the manufacturer's instructions, the genomic DNA of endosperm callus and leaves of mother plants were extracted and purified using a Plant DNA extraction reagent (TRIzol Reagent, Invitrogen). Taxus cuspidata var. nana LEAFY protein gene (GenBank accession No.: HQ245861) and T. chinensis 13-alpha-hydroxylase gene (GenBank accession No.: AY959321) were amplified from genomic DNA, and two pairs of primers were designed for PCR: LE2/f 5'-TGTGGCA AGTTTCT GCTTGA-3', LE2/r $5^{\prime}$-TGCTTTGCATGCCTAAATA CC-3', t6/f 5'-TCAACATTCCCGGA TTCAGT-3', t6/r 5'-TCCTTCCAAGCAATTTCGTC-3', respectively. PCR was performed in a total volume of $20 \mu \mathrm{l}$, and the reaction mix consisted of each of the primers at a concentration of $0.5 \mu \mathrm{M}, 10-50 \mathrm{ng}$ of DNA template, and $10 \mu \mathrm{l} 2$ $\mathrm{X}$ Taq Plantinum PCR MasterMix (Tiangen, Beijing, China). The amplification scheme consisted of 35 cycles of $94{ }^{\circ} \mathrm{C}$ for $30 \mathrm{~s}, 61{ }^{\circ} \mathrm{C}$ for $30 \mathrm{~s}$, and $72{ }^{\circ} \mathrm{C}$ for $45 \mathrm{~s}$, and the final extension is $72{ }^{\circ} \mathrm{C}$ for $7 \mathrm{~min}$. The amplification products were analyzed via $1.2 \%$ agarose electrophoresis and visualized by ethidium bromide staining under UV.

\section{Sequencing and analysis}

Half of the PCR products of endosperm callus and its mother plant were sequenced by Beijing Genomics Institution, in Beijing, China. And the other of them were ligated using by T1pEASY-T1 cloning kit (Tiangen, Beijing, China), in accordance with the manufacturer's instructions. Transformed three $\mathrm{mL}$ of colony culture fluid, and the plasmid was sequenced by Beijing Genomics Institution, in Beijing, China. The DNA sequences were compiled using Chromas software. The online Clustal Omega program (http://www.ebi.ac.uk/ Tools/msa/clustalo/) was applied to multiple sequence alignments.

\section{Data analysis}

Data from callus induction, proliferation of endosperm callus and FCM was assessed by one-way analysis of variance (ANOVA), followed by Duncan's POST-HOC test. A two-tailed $P$ value of less than 0.05 was considered to be statistically significant. All analyses were conducted using SPSS 13.0.

\section{Results and discussion}

Hydropriming and light condition for callus induction

Inhibitors, including of abscisic acid, heptanoic acid, nonanoic acid and acetic acid in endosperm of Taxus genus, are strongly retardant the germination of seed (Le Page-Degivry 1973; Zhang et al. 2007). The hydropriming with water, which allows efficient dormancy broken on embryos have been reported (Zarek 2007; Zhiri et al. 1994). However, these inhibitors could be removed by hydropriming with sterile distilled water for endosperm callus induction, and optimal soaking time was 3 days (Fig. 1a). Compared with sterile distilled water, the $\mathrm{GA}_{3}$ solution couldn't promote the inducible callus (Fig. 1c).
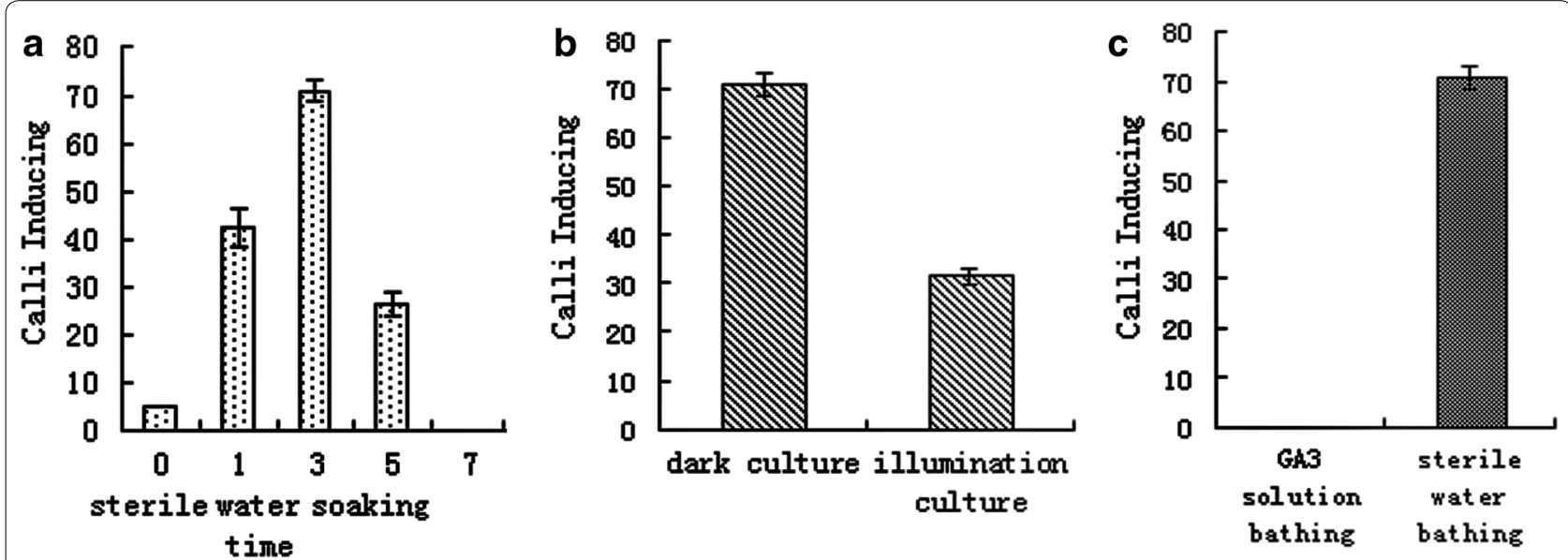

Fig. 1 Effects of seed pre-treatments on callogenesis of T. chinensis Rehd. var. mairei after 4 weeks of in vitro culture. a Total ratio of callus induction with seed soaking in autoclaved deionized water for different time; $\mathbf{b}$ total ratio of callus induction culture under dark and illumination conditions; c total ratio of callus induction with seed soaking in autoclaved deionized water or $3 \mathrm{mg} \mathrm{I}^{-1} \mathrm{GA}_{3}$ solution for 3 days 
Moreover, the inducible ratio was lower under light condition than in darkness (Fig. 1b).

\section{The efficiency of composition of medium on callus induction}

Selection of suitable basic medium, and supplement of proper sort and concentration of plant growth regulators have shown to be the decisive factors on endosperm in vitro cultures (Thomas and Chaturvedi 2008). For the current study, the callus induction and browning ratio were obtained differently based on six dissimilar basic media supplemented with plant growth regulators at the same level in the endosperm of $T$. chinensis var. mairei (Table 1). The lowest callogenesis ratio of endosperm (8.68\%) was obtained from the $\mathrm{SH}$ basic medium, from which the lowest browning ratio was also reliable. Meanwhile, the higher callogenesis was achieved from media of $\mathrm{B}_{5}$ and WPM, and the callus induction ratio was 50.35 and $51.74 \%$, respectively. The $\mathrm{B}_{5}$ medium, with a lower browning ratio, and was followed by BLG, 1/2MS and MS.

The auxins concentration and sort had different effects on endosperm callus induction (Table 2). The control treatment without auxins and cytokinins was acquired a higher callus induction, but endosperm callus died during the subculture. In the meantime, the best callus induction of endosperm from $\mathrm{B}_{5}$ medium, supple-

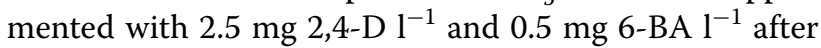
4 weeks of incubation, was observed with the value of 12.75-times higher in contrast with the lowest callus induction (Fig. 2a-f). Interestingly, the callus induction was reduced at a higher concentration of 2,4-D, and the

Table 1 Effective of basic medium on callogenesis of $T$. chinensis Rehd. var. mairei

\begin{tabular}{lcc}
\hline Basic medium & Callus inducing (\%) & Browning ration (\%) \\
\hline BLG & $45.83 \pm 1.04^{\mathrm{b}}$ & $21.10 \pm 1.36^{\mathrm{b}}$ \\
B5 & $50.35 \pm 1.59^{\mathrm{a}}$ & $7.95 \pm 0.25^{\mathrm{e}}$ \\
MS & $39.93 \pm 2.62^{\mathrm{c}}$ & $25.01 \pm 0.91^{\mathrm{a}}$ \\
WPM & $51.74 \pm 1.59^{\mathrm{a}}$ & $16.74 \pm 0.66^{\mathrm{c}}$ \\
SH & $8.68 \pm 0.60^{\mathrm{d}}$ & $0.00 \pm 0.00^{\mathrm{f}}$ \\
1/2MS & $45.14 \pm 2.17^{\mathrm{b}}$ & $11.09 \pm 0.55^{\mathrm{d}}$
\end{tabular}

Means values within a column with the same letters are not significantly different at $5 \%$ level by Duncan's Mutiple Range Test
Table 2 Effective of auxins on endosperm callogenesis of T. chinensis Rehd. var. mairei

\begin{tabular}{lc}
\hline Medium (auxin concentration, $\mathbf{~ m ~ I ~}^{\mathbf{- 1}}$ ) & Ratio of induction (\%) \\
\hline B5 & $57.20 \pm 2.65^{\mathrm{b}}$ \\
B5 + 2,4-D 1.0 + 6-BA 0.5 & $5.56 \pm 2.41^{\mathrm{f}}$ \\
B5 + 2,4-D 2.5 + 6-BA 0.5 & $70.89 \pm 2.31^{\mathrm{a}}$ \\
B5 + 2,4-D 3.5 + 6-BA 0.5 & $55.56 \pm 2.41^{\mathrm{bc}}$ \\
B5 + 2,4-D 4.5 + 6-BA 0.5 & $30.83 \pm 2.20^{\mathrm{d}}$ \\
B5 + NAA 1.0 + 6-BA 0.5 & $52.67 \pm 2.32^{\mathrm{c}}$ \\
B5 + NAA 2.0 + 6-BA 0.5 & $27.03 \pm 2.09^{\mathrm{e}}$ \\
B5 + NAA 4.0 + 6-BA 0.5 & $4.17 \pm 0^{9}$ \\
\hline
\end{tabular}

Means values within a column with the same letters are not significantly different at $5 \%$ level by Duncan's Mutiple Range Test

same situation was observed in medium supplement with NAA (Table 2).

The callus induction was negatively correlated with the 6-BA concentration (Table 3 ). The highest callus induction was obtained in the treatment with $0.5 \mathrm{mg} \mathrm{l}^{-1} 6$-BA and $2.5 \mathrm{mg} \mathrm{l}^{-1} 2,4-\mathrm{D}$. Moreover, no callogenesis was observed when 6-BA was supplemented at the highest concentration.

\section{The ploidy analysis and homozygous identification of endosperm callus}

The chromosome numbers of Taxus species is 24, and the haploid number is 12(Darlington and Dark 1932). The ploidy level can be assessed by chromosome counting and FCM analysis (Germanà 2011). FCM analysis is much easier, convenient and simplified on the determination of ploidy level (Gu et al. 2014; Carloni et al. 2014; Escobedo-GraciaMedrano et al. 2014). The nuclear DNA content, which has the same chromosome number measured by FCM in one genus, is correlated with chromosome numbers. In additional, the nuclear DNA content of genus in Taxus species are range from 22.3 to $24.3 \mathrm{pg}$ (Zonneveld 2012), and the nuclear DAN content of the mother plant was in this range (the data was not shown in this paper). According to those, the ploidy level of endosperm callus and mother plant were investigated by FCM (Fig. 3a, b), and the results indicated that the callus was haploid callus. 

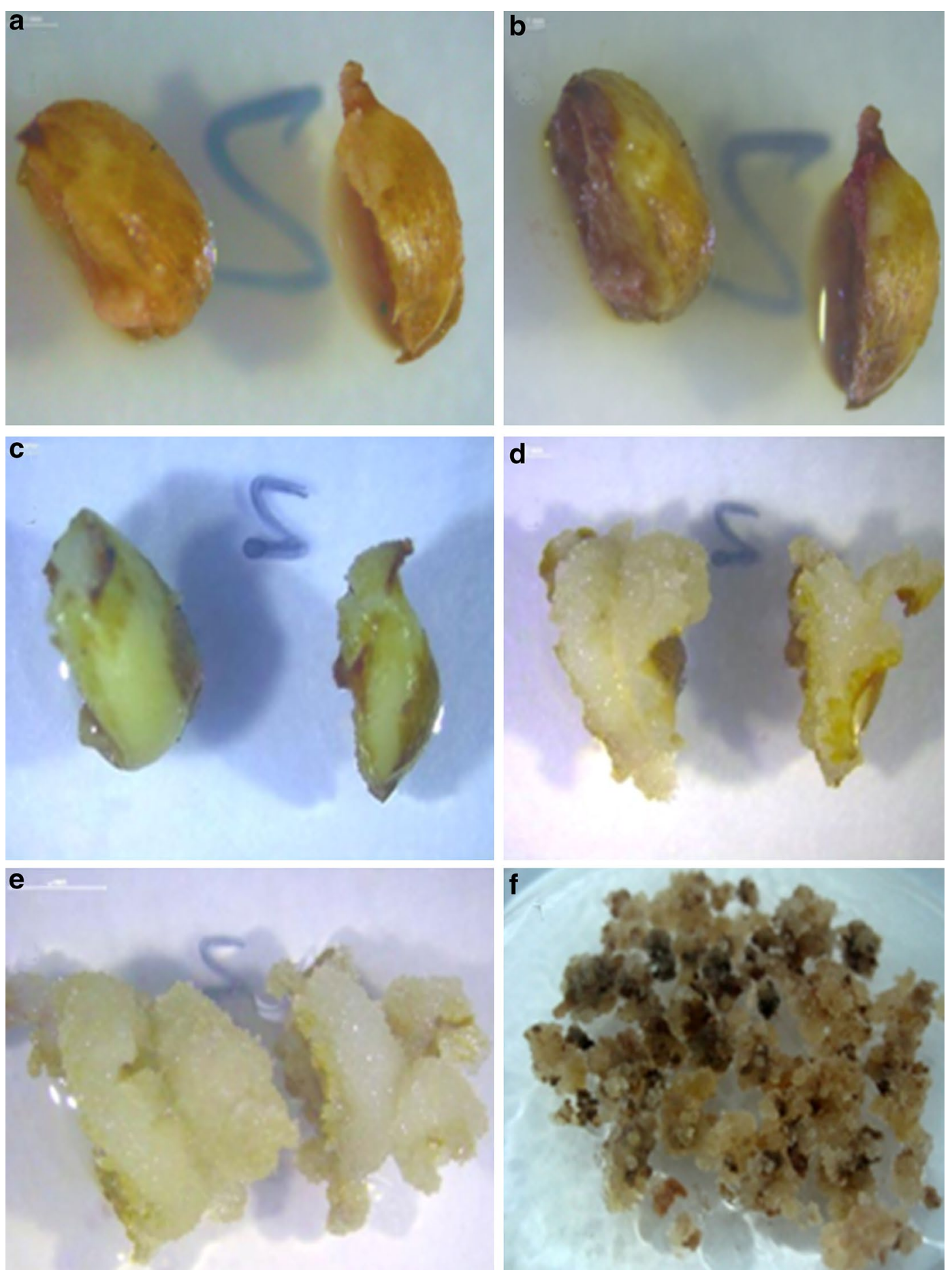

Fig. 2 Aspects of T. chinensis Rehd. var. mairei callus induction from mature endosperm. a Endosperm callus induction on $B_{5}$ medium for 5 days (bar $1 \mathrm{~mm}$ ). b Endosperm callus induction on $B_{5}$ medium for 10 days (bar $1 \mathrm{~mm}$ ). c Endosperm callus induction on $B_{5}$ medium for 18 days (bar $1 \mathrm{~mm}$ ). d Endosperm callus induction on $B_{5}$ medium for 23 days (bar $2 \mathrm{~mm}$ ). e Endosperm callus induction on $B_{5}$ medium for 30 days (bar 2 mm). f Endosperm callus subculture on the proliferation culture medium 
Table 3 Effective of cytokinin on callogenesis of T. chinensis Rehd. var. mairei

\begin{tabular}{lc}
\hline Medium (cytokinins concentration in $\mathbf{~ m ~ I ~ I ~}^{-\mathbf{1}}$ ) & Ratio of induction (\%) \\
\hline B5 + 2,4-D 2.5 + 6-BA 0.5 & $70.89 \pm 2.31^{\mathrm{a}}$ \\
B5 + 2,4-D 2.5 + 6-BA 1.0 & $47.22 \pm 2.41^{\mathrm{b}}$ \\
B5 + 2,4-D 2.5 + 6-BA 2.0 & $30.56 \pm 2.41^{\mathrm{c}}$ \\
B5 + 2,4-D 2.5 + 6-BA 4.0 & $15.28 \pm 2.41_{\mathrm{d}}$ \\
B5 + 2,4-D 2.5 + 6-BA 6.0 & $9.72 \pm 2.41^{\mathrm{e}}$ \\
B5 + 2,4-D 2.5 + 6-BA 10.0 & $0 \pm 0^{\mathrm{f}}$
\end{tabular}

Means values within a column with the same letters are not significantly different at $5 \%$ level by Duncan's Mutiple Range Test

Isozyme analyses, random amplified polymorphic DNA (RAPD) markers and microsatellites have been utilized to assess to homozygosis of regenerated callus and plants (Rai and Shekhawat 2014). The single nucleotide polymorphism (SNP) markers is accelerated application along with the deployment of next-generation sequencing (NGS)
(Thakur et al. 2014). But some projects don't have entire genomic information, and focus on limited number of SNPs in candidate gene studies. Under this circumstances, the very inexpensive, highly flexible SNP genotyping methods, including of homogenous allele-specific PCRbased SNP genotyping method in candidate gene, are needed (Wang et al. 2005). Li et al. (2015) obtained 103 SNPs from 9 pairs of amplification PCR productions, and 84 of them are detected to be homozygous in the 26 loquat (Eriobotrya japonica) cultivars. Our studies were designed to evaluate the LEAFY protein gene and 13-alpha-hydroxylase gene polymorphisms between diploid mother-plant and haploid endosperm of callus. Homozygotic and heterozygotic loci were detected in different PCR amplification production or plasmid of colonies after the sequencing quality was verified by Chromas software (Figs. 4, 5). Three SNPs were detective among three PCR amplification productions in endosperm callus, and one PCR amplification production and two plasmid colonies of diploid plant localizing LEAFY protein gene, including of three
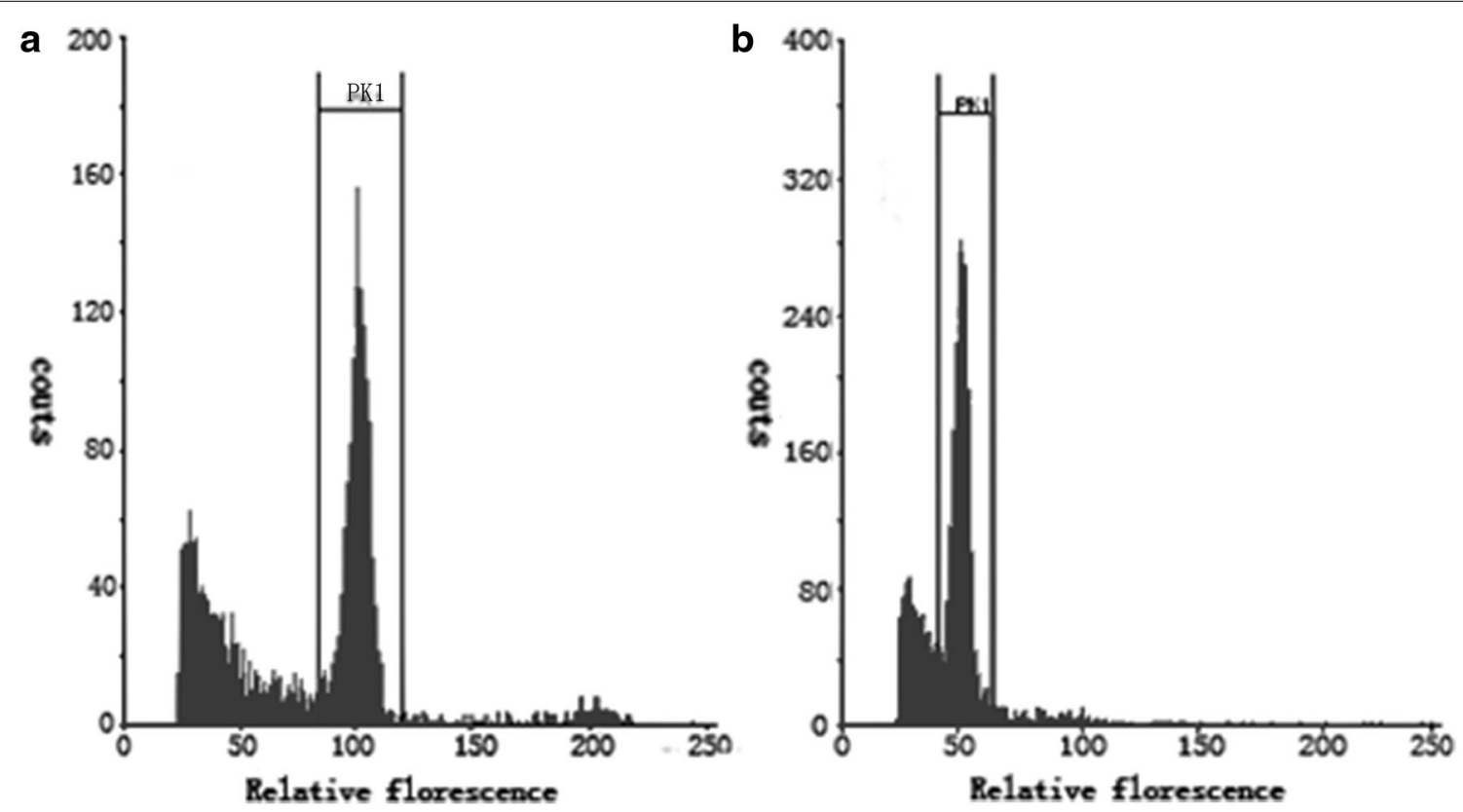

Fig. 3 Histograms of nuclear DNA content obtained after FCM analysis of the DAPI-stained nuclei simultaneously isolated from the leaves and callus of endosperm of T. chinensis Rehd. var. mairei. a Leaves; $\mathbf{b}$ regenerated endosperm callus 


\begin{tabular}{|c|c|}
\hline $\begin{array}{l}1209063475 \mathrm{~J} \\
1209063484 \mathrm{~J}\end{array}$ & 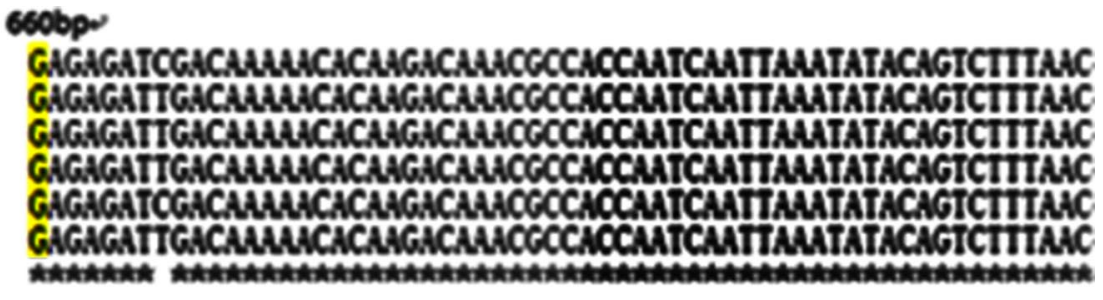 \\
\hline $\begin{array}{l}209063475 J \\
1209063484 J\end{array}$ & 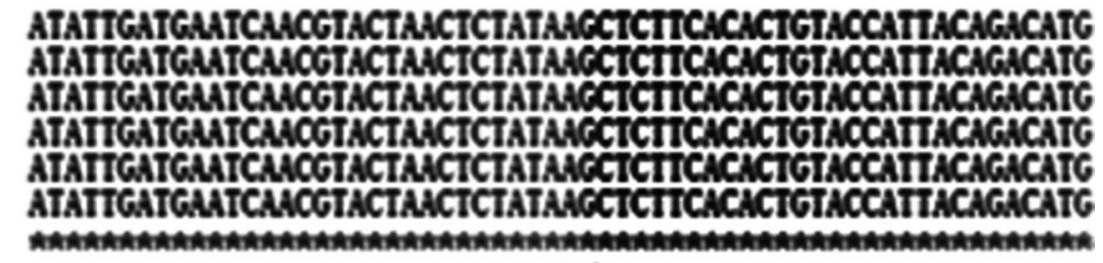 \\
\hline CXL102_1209063475J & 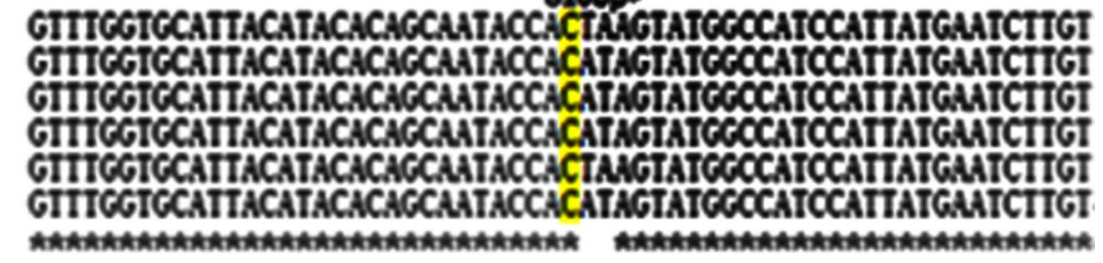 \\
\hline \multicolumn{2}{|c|}{$\begin{array}{l}\text { Fig. } 4 \text { SNP detection from direct sequencing of amplification PCR and PCR plasmid of colonies from endosperm of callus and mother plants by } \\
\text { primers of LE2 (T. cuspidata var. nana LEAFY protein gene, GenBank accession No.: HQ245861). Three SNPs were detective by aligning with CLUSTAL } \\
\text { OMEGA. The HD-12 is sequence of diploid PCR amplification, and two sequences are diploid PCR amplification of plasmid of colonies, including of } \\
\text { HD_8_RV-M_D01_12090643475J and HD_17_RV-M_A02_12090643484J. The HH-2, HH-3 and HH-5 are the sequences of haploid PCR amplifications }\end{array}$} \\
\hline
\end{tabular}

transversions in T/C (1) and A/T (2) (Fig. 4). 16 SNPs were examined among five plasmid colonies of endosperm callus, one PCR amplification production and seven plasmid colonies of diploid plant localizing 13-alpha-hydroxylase gene, consisting of 15 transversions in A/T (6), A/C (4), A/G (2), G/T (3), and one transiton in (G/C) (Fig. 5). The results indicated that the genome typing of endosperm callus was homozygous, and the diploid plant was heterozygous with LEAFY protein gene and 13-alpha-hydroxylase gene of SNP loci analysis.

\section{Conclusion}

We have provided a protocol of homozygous haploid of callus induction. The endosperm of callus was obtained by combination with hydropriming, optimal media, and concentrations of plant growth regular. The results of FCM and PCR-based SNP analysis were provided as an important foundation for further studies on genomic, taxiod-metabolism of functional genomic and bio-fermentation engineering of Taxus plants and other species in secondary metabolisms. 


\section{II-25 \\ DD_t6_3_RV-KLA08_1209074553T LD_t6_4_EV-TLOS_1209074554J

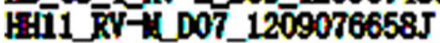 1id t6_5 RV $-\mathrm{C} 0 \mathrm{C}+1209074555 \mathrm{~J}$ 11.t6_24_Rt

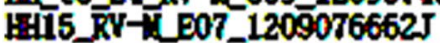 15_t6_12_BV-ti[EO9_1209074591J 1D_t6_27_BY-1LBO9_1209074577J bi-t6_18_RV-TFO8_1209074568J

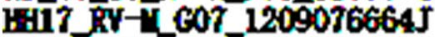 ID_t6_10_ DD_t6_23_BV-ti_H08_1209074573J}

\section{ED-25}

II_t6_3_RV-L 108 1209074553J 1D_t6_4 BV-K

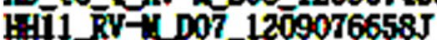
iii_t6_5_kV-4 008 1209074555

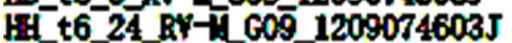
CFI5_kV-VET_1209076662J

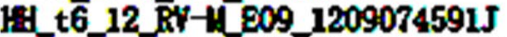
ID_t6_27_BV-1 B09_1209074577J IID_t6_18_BV-H_FOB_1209074568J 19-17_ $\bar{R}$ V ID_t6_10_BV-H D08_1209074560J HD_t6_23_RV-ULHO8_1209074573J
$670 \operatorname{top}$

CTICCTCARICAGTCAGEGTACCTACTACTTAGTACAGACAAAAAAAAAAAARTTAGAG

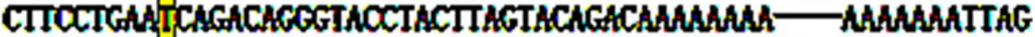
CTTCCTGHICAGACAGEGTACCTACTTAGTACAGACAAAAAMAAA - MAAHAATTAG CTICTCAAICAGACAGEGTACCTACITAGTACAGACAAAAAAAAAA-AAAAAAATAG

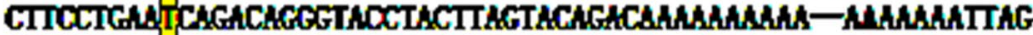
CTTCCTGARICACACAGEGTACCTACTTAGTACAGACAAAAAAAAAA - MAAAAATTAG CTICCIGAAICAGACACEGTACCTACIIAGTACACACAAAAAAAA-AAAAAAATAG

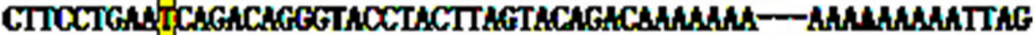
CTICCTGAAICAGTCAGEGTACCTACTACTTAGTACAGACAAAAAAAAAAAARTTAGAG

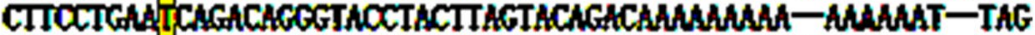

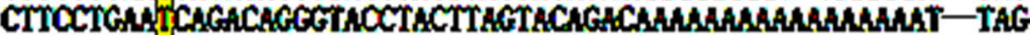
CTICCTGAHICAGACACEGTACCTACITAGTACAGACAAAAAAAAA-AAAAAAAT-TAG

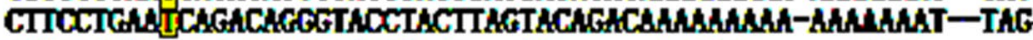

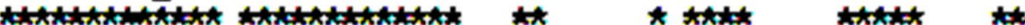

T200p

AGACAGAGAGAGACGAGGATIAAGATICAGAAACGIITCCATAOCTIGACCCACIITI

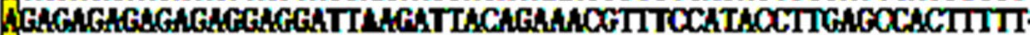
ATACAGAGACAGAGGAGGATTAAGATTACAGAAHOGTTTCCATHOCTTCACCCACITTTI AGACAGACACAGACGACGATTAACATIACAGAA OGTITCCAI

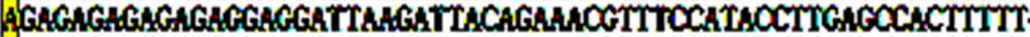
AGAGAGAGAGAGACGAGGATIAACATTACAGAAACGTTTCCATACCTTCACCCACTITIT

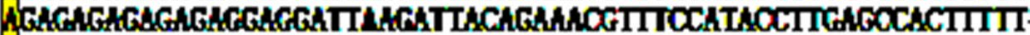
A GAGAGAGACAGACGAGGATTAAGATTACAGAAACGTTTCCATAOCTTGACCCACTTTTT AGAGAGAGAGAGACGACEATIAACATIACAGAAAOGIITCCATHOCTIGAGCCACIITIT AGAGAGHGAGAGMGAGGTT AGACAGAGACAGAGGAGGATAAGATTACAGAAACGTTTCCATACCTTCACCCACTTTTI.

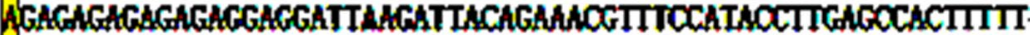

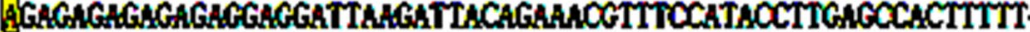

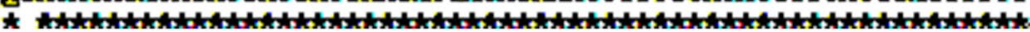

Fig. 5 SNP detection from direct sequencing of PCR amplification and PCR plasmid of colonies from endosperm of callus and mother plants by primers of t6 (T. chinensis 13-alpha-hydroxylase gene, GenBank accession No. AY959321). Sixteen SNPs were detective by aligning with CLUSTAL OMEGA. The HD-25 is sequence of diploid PCR amplification, and seven sequences are diploid PCR amplification of plasmid of colonies, including of HD_t6_3_RV-M_A08_1209074553J, HD_t6_4_RV-M_B08_1209074554J, HD_t6_5_RV-M_C08_1209074555J, HD_t6_27_RV-M_B09_1209074577J, HD_t6_18_RV-M_F08_1209074568J, HD_t6_10_RV-M_D08_1209074560J, HD_t6_23_RV-M_H08_1209074573J. Five sequences are haploid PCR amplification of plasmid of colonies, including of HH_11_RV-M_D07_1209076658J, HH15_RV-M_E07_1209076662J, HH12_RV-M_G 07_1209076664J, HH_t6_12_RV-M_E07_1209 074591J,HH_t6_24_RV-M_G07_1209074603J

\section{Authors' contributions}

$Y L L$ carried out the design and implementation of hydropriming, in vitro culture of endosperm, identification of ploidy level of endosperm callus and extracted DNA from raw materials. JYZ participated in callus induction. ZHZ and TL designed the primers of PCR. FJB sequenced the PCR and plasmids of colonies and analyzed the sequences. SWH and XYX participated in the design and coordination and helped to draft the manuscript. All authors read and approved the final manuscript.

\section{Author details}

${ }^{1}$ Hunan Provincial Key Laboratory of Crop Germplasm Innovation and Utilization, Changsha 410128, Hunan, People's Republic of China. ${ }^{2}$ College of Horticulture and Landscape, Hunan Agricultural University, Changsha 410128, Hunan, People's Republic of China. ${ }^{3}$ The Institute of Vegetables and Flowers, Chinese Academy of Agriculture Sciences, Beijing 100081, People's Republic of China. ${ }^{4}$ State Key Laboratory of Subhealth Intervention Technology, Changsha 410128, Hunan, People's Republic of China.

Competing interests

The authors declare that they have no competing interests.

Received: 6 October 2015 Accepted: 10 May 2016

Published online: 01 June 2016
References

Bi W, Wang Y, Sun G, Zhang X, Wei Y, Li L, Wang X (2014) Paclitaxel-resistant HeLa cells have up-regulated levels of reactive oxygen species and increased expression of taxol resistance gene 1. Pak J Pharm Sci 27(4):871-878

Carloni E, Ribotta A, Colomba EL, Griffa S, Quiroga M, Tommasino E, Grunberg $\mathrm{K}$ (2014) Somatic embryogenesis from in vitro anther culture of apomictic buffel grass genotypes and analysis of regenerated plants using flow cytometry. Plant Cell Tissue Organ Cult (PCTOC) 117(3):311-322

Darlington C, Dark S (1932) The origin and behaviour of chiasmata, II. Cytologia 3(2):169-185

Doležel J, Greilhuber J, Suda J (2007) Estimation of nuclear DNA content in plants using flow cytometry. Nat Protoc 2(9):2233-2244

Escobedo-GraciaMedrano RM, Maldonado-Borges Jl, Burgos-Tan MJ, ValadezGonzález N, Ku-Cauich JR (2014) Using flow cytometry and cytological analyses to assess the genetic stability of somatic embryo-derived plantlets from embryogenic Musa acuminata Colla (AA) ssp. malaccensis cell suspension cultures. Plant Cell Tissue Organ Cult (PCTOC) 116(2):175-185

Foa R, Norton L, Seidman AD (1994) Taxol (paclitaxel): a novel anti-microtubule agent with remarkable anti-neoplastic activity. Int J Clin Lab Res 24(1):6-14

Frense D (2007) Taxanes: perspectives for biotechnological production. Appl Microbiol Biotechnol 73(6):1233-1240 
Germanà MA (2011) Anther culture for haploid and doubled haploid production. Plant Cell Tissue Organ Cult (PCTOC) 104(3):283-300

Gu H, Zhao Z, Sheng X, Yu H, Wang J (2014) Efficient doubled haploid production in microspore culture of loose-curd cauliflower (Brassica oleracea var. botrytis). Euphytica 195(3):467-475

Howat S, Park B, Oh IS, Jin Y-W, Lee E-K, Loake GJ (2014) Paclitaxel: biosynthesis, production and future prospects. New Biotechnol 31(3):242-245

Hussain A, Qarshi IA, Nazir H, Ullah I, Rashid M, Shinwari ZK (2013) In vitro callogenesis and organogenesis in Taxus wallichiana ZUCC, The Himalayan Yew. Pak J Bot 45(5):1755-1759

Kazmi S, Ali S, Jamal S (1991) New bioactive compounds of plant origin. Pak J Pharm Sci 4(2):113-123

Kolewe ME, Gaurav V, Roberts SC (2008) Pharmaceutically active natural product synthesis and supply via plant cell culture technology. Mol Pharm 5(2):243-256

Le Page-Degivry MT (1973) Influence de l'acide abscissique sur le développement des embryons de Taxus baccata L. cultivés in vitro. Zeitschrift für Pflanzenphysiologie 70(5):406-413

Li Y, Zhang G, Pfeifer BA (2014) Current and emerging options for taxol production. In: Jens S, Jörg B (eds) Biotechnology of isoprenoids. Springer, Berlin, pp 405-425

Li X, Xu H, Feng J, Zhou X, Chen J (2015) Mining of genic SNPs and diversity evaluation of landraces in loquat Scientia Horticulturae 195:82-88

Rai MK, Shekhawat N (2014) Recent advances in genetic engineering for improvement of fruit crops. Plant Cell Tissue Organ Cult (PCTOC) 116(1):1-15
Thakur S, Singh PK, Rathour R, Variar M, Prashanthi SK, Gopalakrishnan S, Singh A, Singh U, Chand D, Singh NK (2014) Genotyping and development of single-nucleotide polymorphism (SNP) markers associated with blast resistance genes in rice using GoldenGate assay. Mol Breeding 34(3):1449-1463

Thomas TD, Chaturvedi R (2008) Endosperm culture: a novel method for triploid plant production. Plant Cell, Tissue Organ Cult 93(1):1-14

Wang J, Chuang K, Ahluwalia M, Patel S, Umblas N, Mirel D, Higuchi R, Germer $S$ (2005) High-throughput SNP genotyping by single-tube PCR with $T \sim \mathrm{m}$-shift primers. Biotechniques 39(6):885

Wang X, Xu C, Wu R, Larkins BA (2009) Genetic dissection of complex endosperm traits. Trends Plant Sci 14(7):391-398

Xi X-J, Guo J, Zhu Y-G, Yang X-L, Yu Y, Cheng Z, Li S (2014) Genetic diversity and taxol content variation in the Chinese yew Taxus mairei. Plant Syst Evol 300(10):2191-2198

Zarek M (2007) A practical method for overcoming the dormancy of Taxus baccata isolated embryos under in vitro conditions. Vitro Cellular \& Developmental Biology-Plant 43(6):623-630

Zhang Y-J, Gao H-D, Lu S-B (2007) Germination Inhibitors in Methanol Extract from Taxus chinensis var. mairei Seed. Journal of Nanjing Forestry University (Natural Sciences Edition) 4:16-20

Zhiri A, Jaziri M, Homes J, Vanhaelen M, Shimomura K (1994) Factors affecting the in vitro rapid germination of Taxus embryos and the evaluation of taxol content in the plantlets. Plant Cell, Tissue Organ Cult 39(3):261-263

Zonneveld B (2012) Conifer genome sizes of 172 species, covering 64 of 67 genera, range from 8 to 72 picogram. Nordic Journal of Botany 30(4):490-502

\section{Submit your manuscript to a SpringerOpen ${ }^{\circ}$ journal and benefit from:}

- Convenient online submission

- Rigorous peer review

- Immediate publication on acceptance

- Open access: articles freely available online

- High visibility within the field

- Retaining the copyright to your article

Submit your next manuscript at springeropen.com 